\title{
Cash in Circulation and the Shadow Economy: An Empirical Investigation for Euro Area Countries and Beyond
}

\author{
Franz Seitz \\ Weiden Technical University of Applied Sciences \\ Hetzenrichter Weg 15 \\ D-92637 Weiden \\ Germany \\ Hans-Eggert Reimers \\ University of Technology, Business \\ and Design Wismar \\ Philipp-Müller-Straße 14 \\ D-23966 Wismar \\ Germany \\ Friedrich Schneider \\ Johannes Kepler University Linz \\ Altenberger Straße 69 \\ A-4040 Linz \\ Austria
}

\begin{abstract}
:
We analyze the net cash issues of the national euro area central banks in relation to the dynamics of the shadow economy within a panel cointegration framework. Besides the total net issues, we distinguish between large, medium and small euro banknotes and take due account of other determinants of cash demand as well as country-specific repercussions of the financial crisis of 2008. We find a significant and positive relationship between the net issues and the size of the shadow economy only for medium notes. And this result seems to be driven by the smaller euro area countries. The use of large and small denominations is obviously not driven by the shadow economy. For comparison purposes, we also present panel results for eight non-euro area countries (Australia, Canada, Japan, Norway, Sweden, Switzerland, UK, US). For these countries, we are not able to establish an economically meaningful and statistically significant cash demand equation including the shadow economy.
\end{abstract}

JEL: C23, E41, E58

Keywords: banknotes, net issues, shadow economy, cash demand function, panel cointegration

\section{Introduction and literature review}

In the last decade and especially since the financial and economic crises 2008/09, cash in circulation increased drastically nearly worldwide and faster than GDP due to several reasons (Jobst \& Stix, 2017). One criticism repeatedly levelled at cash for quite some time and which still echoes today is that it is used for illegal activities in the shadow economy and encourages moonlighting, tax evasion and money laundering, in particular. Therefore, there are attempts and proposals in the last few years to abolish cash altogether or certain denominations (e.g., Rogoff, 2016, Part 1) or to restrict the use of cash (eg, Sands, 2016; Sands et al, 2017). Characteristic in this respect is the title of a paper by Peter Sands (2016): "Making it Harder for the Bad Guys: The Case for Eliminating High Denomination Notes". ${ }^{1}$

\footnotetext{
1 Arguments why abolishing cash (or high denomination banknotes) might not be helpful in reducing shadow economic activities can be found in Krüger \& Seitz (2017), ch 7.1 and Schneider (2017).
} 
It is often (implicitly) assumed in this discussion that anonymous transactions are almost exclusively of the illegal kind and that these illegal activities are predominantly undertaken by cash (Buiter, 2009; Sands, 2016).However, empirical evidence to back this hypothesis is lacking. In the debate about stopping the production of the $€ 500$ banknote, ECB Executive Board Member Yves Mersch said: "European Central Bank officials want to see evidence that highdenomination euro banknotes facilitate criminal activity rather than relying on unproven assertions" (Schneeweiss, 2016). The head of the ECB's Currency Management Division also stated that there is no statistically proven link between criminal activity and the use of cash, or, in fact, between the size of the shadow economy and cash (FAZ, 2016). With respect to anonymity, Drehmann et al (2002) wrote: "There are many reasons why people may prefer anonymity - many of which are connected with "bad behavior". But "bad" does not always mean "illegal". It can also include the small human weaknesses we are prone to. Economic agents do not necessarily want these documented in full in the form of proof of payment. Moreover, large-scale crime that involves huge sums of money often prefers cashless means of payment (Mai, 2016). By using complicated and convoluted cross-border chains of transactions, criminals are remarkably adept at concealing the origin of their funds.

The goal of our paper is to shed light on the relationship between the size of the shadow economy and cash in circulation for euro area countries within a banknote demand framework; to our knowledge such an investigation is done for the first time. For that purpose, we use the net issues of banknotes of each individual euro area central bank and estimates of the size of the shadow economy relative to GDP, while controlling for the transactions motive and opportunity costs of holding cash as well as national peculiarities in cash demand. Moreover, the effects of the financial crisis 2008 and the euro crisis 2011/12 are taken into account. We do this in an adequate panel cointegration setup for different denominational subgroups of cash, ie small, medium and large banknotes. We also distinguish between the large (Germany, France, Italy, Spain) and the smaller euro area countries. Finally, we compare the results to those of a panel of non-euro area countries (Australia, Canada, Japan, Norway, Sweden, Switzerland, UK, US). We also augment this panel by the euro area as a whole to investigate whether the results are altered.

The literature on the relationship between cash and the shadow economy is scarce. Since the shadow economy is not directly observable, there are some authors who use indicator variables that are positively related to it, e.g. the share of self-employment to labor force, the share of direct and indirect taxes in GDP or the unemployment rate. Klovland (1984) pursues such an indicator-driven procedure for Sweden and Norway. He finds no effects in the case of Norway, but a positive relationship for Sweden. Using the same methodology, Herwartz et al (2016)investigate whether shadow economic activities have a measurable influence on the demand for currency in a cross section of 11 OECD countries (including Germany, Italy, Norway, Spain and Switzerland) from 1970 to 2012. They find within an error-correction model based on pooled data that some of these variables have a significant influence on cash demand. The latest papers in this vein are Deutsche Bundesbank (2019) and Bartzsch et al (2019) for the case of Germany. Both analyze nine different indicators of the shadow economy within two models: one panel econometric model to explain the banknote lodgements at the Bundesbank branches and one model for domestic banknote demand. Only few of the indicators yield statistically and economically significant results. These are the share of self-employed and the number of drug-related criminal offences in the first model and the burden with taxes and social security contributions in the second.

In line with the positive finding of Klovland (1984) for Sweden is Guibourg \& Segendorf's (2007) analysis of the difference between households' incomes and the expenditures. In their view, this difference captures transactions in the shadow economy which they find to be positively correlated with the unexplained part of cash demand. In contrast, Flannigan \& Parsons (2018) are unable to establish econometrically a meaningful relationship for large denomination bills in Australia, Canada and the UK. By using a survey from 2016 in Austria, Schneider (2016) establishes that only about $10 \%$ of cash is used for shadow economy purposes. In looking at the situation since the beginning of the 2000s, Takala \& Virén (2010) also find that changes in cash demand do not seem to correspond to changes in existing measures of shadow economy, nor do cross-country measures correspond very well with each other. ${ }^{2}$

By analyzing Value Added Tax (VAT) data for 25 EU countries, Immordino \& Russo (2018) find a negative relationship between VAT evasion and card payments for the period 2000 - 2012. Moreover, using cards to access cash at ATMs makes cash more abundant and fosters VAT evasion. Therefore, they conclude that the use of cashless payment instruments hinders tax evasion.

\footnotetext{
${ }^{2}$ In a white paper for "Cash Matters", Dalinghaus (2017) examines a range of institutional, legal, scholarly, policy and news media sources to understand the current state of debate about - and evidence for - the links between cash, crime, and terrorism. It emphasizes that singling out cash when criminal activities depend upon multiple tools and methods is ultimately likely to fail in isolation of restrictions on other tools and methods used by criminals to move money and evade restrictions.
} 
Schneider \& Linsbauer (2016) give a literature review on the finances of international crime organizations which shows that cash is used in many crime activities. Therefore, restrictions of cash have the potential to reduce these activities as transaction costs rise. However, as the private profits of crime activities are very high, the reduction will probably be modest.

Our paper differs in several aspects from the existing literature. First, we are the first to use net issues of cash of all national euro area central banks to analyze the relationship between cash demand and the shadow economy within a currency union. Up to now, these net issues are only investigated for individual countries (see Bartzsch et al, 2013; Rua, 2018), for other currency areas like the US (see Judson \& Porter, 2000, ch 6.4) or, instead, currency (banknotes) in circulation is used (see Herwartz et al, 2016; Klovland, 1984). Second, we distinguish between large and small countries as well as between large, medium and small denominations. Third, we use estimates of the shadow economy which do not rely on the currency demand approach (see, e.g., Medina \& Schneider, 2018, ch 3). ${ }^{3}$ This is necessary to circumvent the circularity problem of estimating the shadow economy with cash figures, and in a subsequent step estimating cash demand functions that include as regressor the size of the shadow economy estimated in the first step (see also Herwartz et al, 2016, 1634f). ${ }^{4}$

The paper is structured as follows: It starts with some theoretical reflections and our basic hypothesis in section 2.Section 3 presents the data and explains the concept of net issues of banknotes and the selected estimation procedure for the shadow economy. Moreover, the econometric methodology is briefly described. The main results for euro area countries as well as a control panel of non-euro area countries are presented in section 4. Section 5 summarizes and concludes.

\section{Some theoretical considerations}

As we showed in the short literature review, there are only few studies (e.g. Herwartz et al, 2016; Schneider, 2017; Guibourg \& Segendorf, 2007)) who use a proper econometric framework to demonstrate minor empirical evidence that the shadow economy positively influences cash or increases the demand for cash. Contrary to this result, Flannigan \& Parson (2018) as well as Takala \& Virén (2010) find no evidence. Empirically, this relationship seems open. Theoretically, we argue, that, when shadow economy activities have been undertaken, mostly cash is used, because cash does not leave a trace (for state authorities), minimizes transaction costs and is completely anonymous. These arguments seem convincing and cash should be an attractive and efficient means when undertaking underground activities. However, which denominations are mostly used is theoretically open. High-denomination notes should be the most attractive ones. This is theoretically plausible but depends on the one side on the size of the shadow economy payment, and on the other side on whether high-denomination banknotes are accepted in day-to-day life. From these considerations, we formulate the following hypothesis:

"A growing shadow economy increases the amount of cash in circulation, ceteris paribus. The concrete denomination which will be predominantly used, is ambiguous."

In the next paragraphs, we will empirically test this hypothesis for the case of euro area countries and, as a robustness check, also for non-euro area countries.

\section{Data issues and econometric methodology}

Although shadow economic activities have been studied for a long time, the discussion regarding the "appropriate" methodology to assess them has not come to an end yet. Generally, the size of the shadow economy can be measured in two ways: at the micro level using surveys or questionnaires; alternatively, indirect methods such as the currency demand or latent Multiple Indicators Multiple Causes (MIMIC) approach making use of macroeconomic indicators can be used (see, eg, Medina \& Schneider, 2018, ch 3). The virtue of the latter is that the shadow economy is formalized as the outcome of a multitude of measurable causes like tax rates, the degree of regulation, or the level of unemployment. While those methods allow approximating the development of the shadow economy over time, direct approaches better reveal the motivation of individuals to escape into the shadow economy. In recent years, indirect estimation of the shadow economy is mostly based on the MIMIC procedure and/or the currency demand method. Due to methodological reasons and our research question, i.e. to avoid an identification problem, we rely on the MIMIC approach without cash. To be more concrete, we use the following indicator variables in our estimation: (1) labor force participation rate, (2) light intensity rate, and (3) growth rate of GDP (Medina \& Schneider, 2018, chapter 3C). As the most commonly used

\footnotetext{
${ }^{3}$ Pickhardt \&Sardà (2012) modify this approach by taking due account of hoarded cash and foreign demand for cash.

${ }^{4}$ If cash is necessary to get efficient estimates of the shadow economy, this might result in distorted results. 
monetary indicator variables, the light intensity indicator variable also reflects additional shadow economy activities quite well as many of them are undertaken at night. ${ }^{5}$

Our measure of the shadow economy refers to the hidden economy, i.e., activities that clearly fall in the production boundary of the System of National Accounts, but are deliberately concealed from public authorities (UN et al, 2009, § 6.40). ${ }^{6}$ These activities are quite common in the household sector. Examples are baby-sitting, extra tuition for pupils, paying the cleaning woman, repairing a car or building a house.

The cash series we use is the net banknote issues of euro area central banks. The total volume of banknotes in circulation (including banks' vault cash) corresponds to the cumulated net issuance, ie the cumulated difference between monthly withdrawals and lodgments at the respective national central banks. However, it is not identical to the circulation of banknotes in the respective country as the banknotes can freely flow from one euro area country to another and as all national issues are perfect substitutes for each other. Nevertheless, the net issues should be closely related to economic activities and developments in the country. Due to cross-border migration flows the net issues can even be negative for some countries (see Rua, 2018, for the case of Portugal with high tourism inflows). As the demand for euro banknotes from outside the euro area is mainly satisfied via Germany, the Deutsche Bundesbank records very high net issues of banknotes (see Bartzsch et al, 2013). Both, the traditional national determinants of cash demand (transactions and hoarding motive) as well as the national peculiarities have to be taken into account in the econometric specification (see below). As the influence of the shadow economy might differ depending on the denomination considered, we differentiate between small (cash_sm: $€ 5, € 10, € 20)$, medium (cash_mi: $€ 50, € 100)$ and large (cash_la: $€ 200, € 500)$ banknotes. $^{7}$

As shadow economic activities are not the only potential determinant of cash demand, we control for the transactions and opportunity cost (hoarding) motives of holding cash. The transactions variable is captured by private nominal consumption and nominal disposable income, respectively. The data are taken from the AMECO database of the European Commission. Our main focus is on the consumption variable as is usual in macro studies on cash demand (see, eg, Bartzsch \& Seitz, 2016; Fischer et al, 2004; Rua, 2018). Opportunity costs are proxied by a short-term interest rate. More specifically, we use interest rates of household deposits with agreed maturity from the ECB Statistical Data Warehouse.

We consider all euro area countries since they have introduced the euro, except Cyprus and Malta (no data on the shadow economy available) and Lithuania (euro area accession in 2015). Consequently, our annual sample runs form 2002-2017 or shorter with at most 16 countries, ie we have an unbalanced panel structure. ${ }^{8}$

The trend behavior of the variables included necessitates an analysis of their stationarity properties to determine an appropriate specification of the empirical model. However, it is well-known that standard unit root and cointegration tests suffer a short sample bias, ie they have low power against stationary alternatives. Panel tests improve the situation in this respect as they augment the time series dimension by the cross section. Consequently, inference is based on a broader information set with resulting gains in power and more reliable statistical inference.

Our main interest is to establish a meaningful panel cointegration relationship for the different specifications. Thus, the cash demand equations should be statistically significant and economically valid in having the theoretically expected signs, ie a positive sign for the transaction and shadow economy variable and a negative sign for the interest rate. As there might be national peculiarities besides transactions demand, hoarding and the shadow economy, we estimate the regressions with fixed country effects. Reasons for this decision are, for instance, foreign demand in the case of Germany (see Bartzsch et al, 2013) or tourism flows in the case of southern European countries (see Rua, 2018).

Panel unit root tests generalize the unit root tests for single series to cross section data sets. We apply a battery of these tests. These include the common root approach of Levin, Lin \& Chu (2002) as well as the method of a common unit root of Breitung (2000). Both approaches share the assumption that there is a common unit root process, which is identical across the cross sections. The respective null hypothesis is the existence of a unit root. The individual unit root approaches of Im, Pesaran \& Shin (2003) (IPS) and the two Fisher tests (ADF and PP) combine individual unit root tests to determine a panel test statistic (see, e g, Maddala \& Wu, 1999).

\footnotetext{
${ }^{5}$ Another often used indicator variable is electricity consumption, see Williams \& Schneider (2016).

${ }^{6}$ A discussion of the definition of the shadow economy may be found in appendix B.

${ }^{7}$ See Bartzsch \& Seitz (2016) for the case of Germany.

${ }^{8}$ See for an analysis of cash payments and receipts of the cash offices in the US within a panel framework Judson \& Porter (2001, ch5.2).
} 
The IPS relies on the t-statistics of the ADF regression. The Fisher-ADF and the Fisher PP use p-values from individual unit root tests. All these approaches allow for individual intercepts to model individual fixed effects or individual intercepts and individual trends. The optimal lag lengths are in each case selected using the criterion of Hannan-Quinn (H-Q).

Due to the non-stationarity of the variables, the next natural step is to test for a cointegrating relationship. Pedroni (2004) suggests residual based tests for the null of no cointegration under the assumption of a heterogeneous panel. He suggests two classes of tests. The first is based on pooling the residuals of the Engle-Granger type regression along the within dimension of the panel. Besides the individual approach, cross sectional dependency is taken into account by weighting which uses a generalized least squares method based on the estimation of the panel-wide asymptotic covariance matrix. The second uses the pooling of the residuals adopting the between-dimension of the panel. The test of Kao (1999) follows the same basic approach as the Pedroni tests, but requires homogeneous coefficients of the cointegrating relationship and allows for country-specific intercepts. We use the augmented version of the test. Finally, the combined test (FisherJohansen) evaluates the results (p-values) of individual Johansen trace cointegration tests (see Maddala \& Wu, 1999). The multitude of tests applied (unit root, cointegration) should be regarded as a kind of robustness check of our results.

If there is evidence for cointegration, it is of interest whether the relationship might be interpreted as a cash demand equation including the shadow economy. Pedroni (2001) suggests a panel estimator for one cointegrating relationship as an extension of the fully modified OLS estimator of Phillips \& Hansen (1990) called panel fully modified OLS (PFMOLS). The OLS estimator is a super-consistent estimator of the coefficients of cointegrated variables. Often used variants are the Pedroni (2001) and Mark \& Sul (2003) procedures which are based on a consistent estimator of the moments of the regressors. Moreover, the authors propose an extension of the Stock \& Watson (1993) estimator for panels known as panel dynamic OLS (P-DOLS). This estimator uses lags and leads of the explanatory variables to reduce the asymptotic endogeneity and serial correlation. In our case with annual data, we restrict the leads and lags to one or select the lag-lead structure depending on the information criterion of Hannan- Quinn. ${ }^{9}$ In a simulation study Wagner \& Hlouskova (2012) show that the P-DOLS estimator performs best across a large set of experiments. They confirm evidence of Kao \& Chiang (2001). Therefore, we prefer and present the results of the P-DOLS methodology. ${ }^{10}$

\section{Results}

\subsection{Euro area countries}

Descriptive statistics of the euro area country data on the share of the shadow economy in GDP (se) and the different cash variables are given in the appendix A. It covers the mean, minimum, maximum and standard deviation, respectively (see tables 1A to 5A). Additionally, some contemporaneous correlations on total (relative) cash changes are shown (see table $6 \mathrm{~A}$ ). The values of se vary between $7 \%$ and $33 \%$ and have relatively small standard deviations. The means of the total cash issues are negative in Austria and Portugal, whereas they are positive in all other countries. The highest values are those for Germany which is also true for the three sub-groups. For the different denominational groups, the situation is more diverse. With respect to the large denominations, Belgium, Latvia and Portugal have negative means. Outstanding is Italy with a minimum of $€$ bn -46.8 at the large denominations and a huge standard deviation of $€$ bn 45 at the medium denominations. The decrease of the net issues of the medium denominations in Austria, Slovenia and Portugal may be related to tourism flows. And the growing importance of cashless payments may explain the average decline of small denominations in the Netherlands and Estonia. The bivariate correlations between the countries vary between-0.96 (Finland - Luxembourg) to +0.98 (Finland - Ireland). For Portugal (Austria), there are 9 (10) negative correlations, which may indicate the importance of tourism flows for the cash developments in these countries. However, the correlations are relatively low; they are all below $30 \%$ (in absolute values), as most of the negative correlations in the sample.

Table 1 comprises the results of the panel unit root tests. As some countries have negative net issues of banknotes in certain years, the cash variables are in absolute values, not in logarithms. The short-term interest (in) and the share of the shadow economy in GDP (se) are also in absolute values (percentages). However, the two transactions variables private consumption (cons) and disposable income (inc) are in logs (l). The second column indicates the specification of the deterministic part in the test regressions. The coefficients of this part are country-specific. The null hypothesis of a common unit root of the LLC tests is rejected in nearly all the cases, whereas the more general null of the IPS, ADFF

\footnotetext{
${ }^{9}$ An alternative estimation method would be a vector error correction model. However, this approach is not implementable for panels given the high number of parameters to estimate (see Christiansen et al, 2009).

${ }^{10}$ Results of the P-FMOLS case are available upon request. 
and PPF is usually not rejected for the level variable (as it is for the reported Breitung test). However, it is generally rejected for the change $(d)$ of the variables. Therefore, we conclude that all variables are I(1).

Table 1: Panel unit root tests

\begin{tabular}{|c|c|c|c|c|c|c|c|}
\hline Variable & $\begin{array}{l}\text { Test } \\
\text { specification }\end{array}$ & LLC & Breitung & IPS & $\mathrm{ADFF}$ & PPF & $\begin{array}{l}\text { Desi- } \\
\text { cion }\end{array}$ \\
\hline cash & intercept $+\mathrm{tr}$ & $-4.13 * * *$ & 0.50 & -0.43 & 37.51 & $77.43 * * *$ & \multirow[t]{2}{*}{$\mathrm{I}(1)$} \\
\hline $\mathrm{d}($ cash $)$ & intercept & $-6.95 * * *$ & - & $-4.67 * * *$ & $73.48 * * *$ & $68.43 * * *$ & \\
\hline cash_la & intercept $+\mathrm{tr}$ & $-5.10 * * *$ & 1.80 & 0.12 & 37.17 & $41.21 *$ & \multirow[t]{2}{*}{$\mathrm{I}(1)$} \\
\hline d(cash_la) & intercept & $-2.90 * * *$ & - & -0.94 & 37.16 & $60.71 * * *$ & \\
\hline cash mi & intercept $+\mathrm{tr}$ & 0.49 & 3.89 & 2.59 & 21.02 & 24.26 & \multirow[t]{2}{*}{$\mathrm{I}(1)$} \\
\hline d(cash_mi) & intercept & $-1.61 *$ & - & -0.39 & $51.38 * * *$ & 39.64 & \\
\hline cash_sm & intercept $+\operatorname{tr}$ & -1.07 & 1.66 & 2.12 & 25.21 & 23.42 & \multirow[t]{2}{*}{$\mathrm{I}(1)$} \\
\hline $\mathrm{d}($ cash_sm) & intercept & $-4.62 * * *$ & - & $-1.76 * *$ & $59.77 * * *$ & $48.76 * * *$ & \\
\hline in & intercept & $-2.40 * * *$ & - & 0.30 & 25.08 & 22.51 & \multirow[t]{2}{*}{$\mathrm{I}(1)$} \\
\hline $\mathrm{d}($ in) & intercept & $-10.94 * * *$ & - & $-7.24 * * *$ & $113.35 * * *$ & $125.22 * * *$ & \\
\hline lcons & intercept $+\mathrm{tr}$ & $-4.22 * * *$ & -0.70 & -0.31 & 31.82 & 14.41 & \multirow[t]{2}{*}{$\mathrm{I}(1)$} \\
\hline $\mathrm{d}($ lcons $)$ & intercept & $-6.22 * * *$ & - & $-4.01 * * *$ & $65.73 * * *$ & $58.55 * * *$ & \\
\hline linc & intercept + tr & $-4.07 * * *$ & $-3.30 * * *$ & $-1.37 *$ & 39.16 & 23.98 & \multirow[t]{2}{*}{$\mathrm{I}(1)$} \\
\hline $\mathrm{d}($ linc $)$ & intercept & $-7.17 * * *$ & - & $-5.50 * * *$ & $86.18 * * *$ & $87.28 * * *$ & \\
\hline $\mathrm{se}$ & intercept & $-1.72 * *$ & - & -0.93 & 40.11 & $43.57 *$ & \multirow[t]{2}{*}{$\mathrm{I}(1)$} \\
\hline $\mathrm{d}(\mathrm{se})$ & intercept & $-11.90 * * *$ & - & $-8.20 * * *$ & $121.65^{* * *}$ & $126.68 * * *$ & \\
\hline
\end{tabular}

Notes: Cash: total banknotes; cash_la (cash_mi, cash_sm): large (medium, small) denominations; in: interest rate; lcons (linc): $\log$ of private consumption (disposable income); se: shadow economy; d: difference operator. Bandwidth selection using Hannan-Quinn criterion; LLC: Levin, Lin \& Chu t-statistic, Breitung: Breitung t-statistic (only available for specifications with intercept and trend), IPS: Im, Pesaran \& Shin W-statistic, ADFF: ADF-Fisher Chi²-statistic, PPF: PPFisher Chi ${ }^{2}$-statistic; Newey-West automatic bandwidth selection and Bartlett kernel; *** $(* *, *): 1(5,10)$ percent significance level.

Due to the non-stationarity of our variables, we conduct panel cointegration tests in a second step. These are presented in table 2. It includes the systems containing the variables cash (including subgroups), se, in and lcons. As mentioned, we concentrate on the transaction variable lcons. Using this transaction variable, the tests do not reveal unambiguous results. There is evidence of a cointegrating relationship for all cash specifications. ${ }^{11}$ Most of the tests reject the null of no cointegration. If at all, the weakest evidence of cointegration is found for the small denominations.

${ }^{11}$ The evidence is weaker for systems including linc. These results are available upon request. 
Table 2: Panel cointegration tests

\begin{tabular}{|c|c|c|c|c|c|c|c|c|}
\hline \multirow[t]{2}{*}{ Test statistic } & \multicolumn{2}{|c|}{ Variables: cash, se, in, lcons } & \multicolumn{2}{|c|}{$\begin{array}{l}\text { Variables: cash_la, se, in, } \\
\text { lcons }\end{array}$} & \multicolumn{2}{|c|}{$\begin{array}{l}\text { Variables: cash_mi, se, in, } \\
\text { lcons }\end{array}$} & \multicolumn{2}{|c|}{$\begin{array}{l}\text { Variables: cash_sm, se, in, } \\
\text { lcons }\end{array}$} \\
\hline & Individual & Weighted & Individual & Weighted & Individual & Weighted & Individual & Weighted \\
\hline $\begin{array}{l}\text { Pedroni: } \\
\text { Panel } v\end{array}$ & $2.46^{* * *}$ & $3.32 * * *$ & $17.58 * * *$ & $2.14 * *$ & $4.09 * * *$ & $3.46^{* * *}$ & $25.1 * * *$ & $4.43 * * *$ \\
\hline Panel $\rho$ & 3.87 & 2.88 & 2.02 & 3.27 & 4.08 & 3.79 & 3.50 & 3.04 \\
\hline Panel PP & 2.78 & $-1.46^{*}$ & $-2.13 * *$ & 0.14 & 4.32 & 1.61 & 2.98 & 1.09 \\
\hline Panel ADF & $-1.71 * *$ & $-5.67 * * *$ & $-4.80 * * *$ & $-4.73 * * *$ & $-2.92 * * *$ & $-3.39 * * *$ & $-2.60 * * *$ & -0.80 \\
\hline Group $\rho$ & \multicolumn{2}{|l|}{4.42} & \multicolumn{2}{|l|}{4.35} & \multicolumn{2}{|l|}{5.09} & \multicolumn{2}{|l|}{5.17} \\
\hline Group PP & \multicolumn{2}{|l|}{$-1.66^{* *}$} & \multicolumn{2}{|l|}{$-2.73 * * *$} & \multicolumn{2}{|l|}{-0.23} & \multicolumn{2}{|l|}{2.57} \\
\hline Group ADF & \multicolumn{2}{|l|}{$-6.22 * * *$} & \multicolumn{2}{|l|}{$-5.75 * * *$} & \multicolumn{2}{|l|}{$-5.00 * * *$} & \multicolumn{2}{|l|}{$-1.37 *$} \\
\hline Kao ADF & \multicolumn{2}{|l|}{1.14} & \multicolumn{2}{|l|}{0.41} & \multicolumn{2}{|l|}{$1.86 * *$} & \multicolumn{2}{|l|}{$1.86 * *$} \\
\hline $\begin{array}{l}\text { Fisher Johan- } \\
\text { sen trace } r=0\end{array}$ & \multicolumn{2}{|l|}{$380.0 * * *$} & \multicolumn{2}{|l|}{$326.0 * * *$} & \multicolumn{2}{|l|}{$360.8 * * *$} & \multicolumn{2}{|l|}{$326.7 * * *$} \\
\hline $\begin{array}{l}\text { Fisher Johan- } \\
\text { sen trace } r \leq 1\end{array}$ & \multicolumn{2}{|l|}{$119 * * *$} & \multicolumn{2}{|l|}{$129.9 * * *$} & \multicolumn{2}{|l|}{$154.6 * * *$} & \multicolumn{2}{|l|}{$161.2 * * *$} \\
\hline
\end{tabular}

Notes: Pedroni tests: lag length automatically selected by H-Q criterion, individual intercept and individual trend; Fisher Johansen test: lag length of the dynamic part 1 , with intercept in cointegrating equation and VAR. *** $(* *, *): 1(5,10)$ percent significance level. As there is evidence of cointegration between the four variables, a natural last step is to investigate whether the relation might be interpreted as a sensible and economic meaningful cash demand equation. In our view and to be more specific, this means finding a relation that exhibits a positive and statistically significant influence from the shadow economy given the repercussions from the transactions variable and opportunity costs. Moreover, country-specific peculiarities in the form of fixed country effects should be taken into account in the unbalanced panel. ${ }^{12}$

The results of the estimated long-run coefficients are given in the Table 3 . The first column shows the normalized variable which is the different banknote series. These are measured in $€$ billion. The second column presents the P-DOLS specification. We estimate in each case with fixed effects, either with equal weighting of all observations or with crosssection weights. ${ }^{13}$ The latter estimates a GLS specification assuming the presence of cross-section heteroscedasticity. The next columns contain the estimates of the regression coefficients of the explanatory variables given in the heading row of the table. Therefore, the read of, for instance, the first row is as following:

$\operatorname{cash}_{t, i}=c_{i}+0.6 \mathrm{bm}_{t, i}-14.2 \mathrm{in}_{t, i}+77.7$ lcons $_{t, i}$

The high numbers are due to the non-logarithmizing of the cash variable. Some interesting findings emerge from table 3. First, a statistical significant relation with the expected signs seems to exist for total cash issues and the medium denominations ( $€ 50$ and $€ 100)$. Especially, the shadow economy variable has the expected positive sign. Obviously, the influence of the shadow economy stems from the medium denominations. Against the background of the definition of our shadow economy variable (see section 2), this seems intuitively plausible. Second, in the case of the large denominations, each of the three explanatory variables is individually statistically significant, but the shadow economy has the wrong sign. Third, there is no evidence of a cash demand equation for the small denominations: neither are the individual coefficients statistically significant nor is there a positive coefficient of the shadow economy. This is in line

12 An alternative would be to include a deterministic (common or country-specific) trend in the different estimations which might, inter alia, capture the influence of omitted variables, e.g., cashless payment instruments. Implementing this idea yields significant (positive or negative) trends for some some countries and some positive significant shadow economy coefficients even for the large denominations. In total, we have 7 out of 16 significant shadow economy influences (see appendix C1). However, the final equations perform worse than the ones presented in the main text. Moreover, there are economic and econometric reasons not to follow this approach. The economic reason is that the trend is a catch-all variable which may represent any influence and takes over the influence of other individual variables included. The econometric argument refers to the implications of different deterministic specifications in a cointegrated VAR system (Juselius, 2006, 100). A linear trend in a cointegrating relationship implies that the model includes trend stationary variables or a trend stationary cointegrating equation which is very seldom the case. These complications are circumvented by assuming no deterministic trend in the cointegrating relationship. In that way, this long-run relation absorbs possible linear trends in the variables.

${ }^{13}$ The results of the P-FMOLS and the Engle-Granger procedure are available upon request. They also indicate mixed evidence. 16 
with the implications from table 2 where we found the weakest evidence for cointegration in the case of the small denominations. Fourth, the results do not depend on weighting or not weighting the observations. ${ }^{14}$

Table 3: Cointegrating relationship estimates

\begin{tabular}{|c|c|c|c|c|c|}
\hline Variable & Specification & \multicolumn{3}{|c|}{ Explanatory variables } & \\
\hline & & se & in & lcons & $\mathrm{R}^{2}$ \\
\hline cash & c, no weights & 0.6 & $-14.2 * * *$ & 77.7 & 0.89 \\
\hline cash & c, weights & $7.1 * * *$ & $-5.0 * * *$ & $95.0 * * *$ & 0.92 \\
\hline cash la & c, no weights & $-5.8 * * *$ & $-6.9 * * *$ & 6.9 & 0.89 \\
\hline cash la & c, weights & $-5.0 * * *$ & $-32.2 * * *$ & $-5.0 * * *$ & 0.87 \\
\hline cash mi & c, no weights & $7.2 * * *$ & $-6.0 * *$ & $65.4 * *$ & 0.87 \\
\hline cash_mi & c, weights & $4.8 * * *$ & $-4.7 * * *$ & $54.7 * * *$ & 0.88 \\
\hline cash sm & c, no weights & -0.7 & -1.4 & 5.4 & 0.85 \\
\hline cash_sm & c, weights & -0.2 & 0.2 & 2.7 & 0.83 \\
\hline
\end{tabular}

Notes: Unbalanced panel; pooled DOLS estimates with fixed 1 lead and 1 lag; equations deterministics $\mathrm{c}$ as fixed effects using no or cross-section weights; $* * *(* *, *): 1(5,10)$ percent significance level.

What about magnitudes? These are of special interest as the proponents of cash abolition argue that the shadow economy is the main driver of the increase in cash demand. Let us concentrate on all banknotes and the specification with weighting. If the share of the shadow economy in GDP decreases by one percentage point, the demand for banknotes would fall by about 7 billion euros. In the euro area, the estimates of the shadow economy are in the range of about 18 $\%$ of GDP in 2017 (see Medina \& Schneider, 2018). Consequently, reducing the shadow economy by $50 \%$ diminishes the demand for banknotes by about 65 billion euros. This is approximately $5 \%$ of total banknotes in circulation at the end of 2017.Let us assume that all shadow economic activities are settled in cash and that the velocity of circulation of cash in the shadow economy is around 10 (see Krüger \& Seitz, 2017, fn 60). Then, abolishing euro cash altogether would, ceteris paribus, eliminate a shadow economy value of about $€ 200$ billion. This equals $1.8 \%$ of euro area GDP at the end of 2017. An important driver for the cash holding is usually transactions. In our case, a one percent increase in consumption stimulates net cash issues in the euro area by about 95 billion euro, i.e., an increase of consumption by 100 billion euro raises cash in circulation by only 1.68 billion euros. Moreover, an increase of the interest rate by one percentage point reduces the cash in circulation by 5 billion euros. Hence, the influence of shadow economy in terms of changes in percentage points relative to GDP seems to be as important as a percentage point change in the interest rate. However, these magnitudes are significantly lower than those of a one percent change in private consumption.

Table 4: Pooled cointegrating relationships: different country groupings

\begin{tabular}{|c|c|c|c|c|c|c|}
\hline \multirow[t]{2}{*}{ Variable } & \multirow{2}{*}{$\begin{array}{l}\text { Specifi- } \\
\text { cation }\end{array}$} & \multirow[t]{2}{*}{ Panel } & \multicolumn{4}{|c|}{ Explanatory variables } \\
\hline & & & se & in & lcons & $\mathrm{R}^{2}$ \\
\hline cash & $\mathrm{c}$ & All countries & $7.1 * * *$ & $-5.0 * * *$ & $95.0 * * *$ & 0.92 \\
\hline cash & $\mathrm{c}$ & Big 4 & $-23.3 *$ & $-30.7^{*}$ & $484.0 * * *$ & 0.91 \\
\hline cash & $\mathrm{c}$ & Other countries & $4.9 * * *$ & $-4.6 * * *$ & 0.9 & 0.90 \\
\hline cash la & $\mathrm{c}$ & All countries & $-5.0 * * *$ & $-32.2 * * *$ & $-5.0 * * *$ & 0.87 \\
\hline cash_la & $\mathrm{c}$ & Big 4 & $-20.1 * * *$ & $-23.3 * * *$ & -63.7 & 0.91 \\
\hline cash_la & $\mathrm{c}$ & Other countries & -0.9 & $-1.2 *$ & 4.1 & 0.84 \\
\hline cash_mi & $\mathrm{c}$ & All countries & $4.8 * * *$ & $-4.7 * * *$ & $54.7 * * *$ & 0.88 \\
\hline cash_mi & $\mathrm{c}$ & Big 4 & -7.3 & -10.4 & $332.0 * * *$ & 0.90 \\
\hline cash_mi & $\mathrm{c}$ & Other countries & $6.2 * * *$ & $-2.4 * *$ & $20.7 * *$ & 0.84 \\
\hline cash_sm & $\mathrm{c}$ & All countries & -0.2 & 0.2 & 2.7 & 0.83 \\
\hline cash sm & $\mathrm{c}$ & Big 4 & -3.3 & $-4.6^{*}$ & $151.0 * * *$ & 0.96 \\
\hline cash_sm & $\mathrm{c}$ & Other countries & 0.1 & -0.3 & $10.2 * * *$ & 0.84 \\
\hline
\end{tabular}

Notes: Unbalanced panel; pooled DOLS estimates with fixed 1 lead and 1 lag; equations deterministics $\mathrm{c}$ as fixed effects using cross-section weights; *** $(* *, *): 1(5,10)$ percent significance level.

\footnotetext{
${ }^{14}$ An estimation of the panel in first differences of the variables, despite evidence of cointegration, would yield in some instances even significant positive results for the large denominations. In total, we get significant results in 10 out of 24 cases (see appendix C). However, for econometric and statistical reasons, we rely more on the panel cointegration results.
} 
As a robustness check and kind of sensitivity analysis, we divide the whole cross section of countries into the big four countries France, Germany, Italy, Spain (Big 4) and the rest of the smaller euro area countries (other countries). We concentrate on the DOLS (with weighting) estimates with fixed effects. In table 4 the third column indicates the panels considered where for comparison purposes "all countries" replicates the estimates of table 3 . Interestingly, the result that the medium denominations are positively influenced by the shadow economy (given the effects of the control variables) seems to be driven by the smaller euro area countries. For the panel including France, Germany, Italy and Spain, the se coefficient is significant, but with the wrong negative sign. Turning to the large denominations,seis in any case negative. The estimated coefficients of the small denominations are mostly not significant. Within no country grouping are we able to explain the use of the small denominations in a meaningful way with the included variables and effects.

Up to now, we did not try to include an influence of the financial crisis in 2008/09. This crisis had a major influence on cash demand in several euro area countries (see, e.g., ECB, 2018; Deutsche Bundesbank, 2016, 33f). Therefore, disregarding its repercussions might distort our results. We model the financial crisis as either an impulse dummy(with a value of one in 2009 and zero otherwise) or a step dummy (taking the value of one from 2009 onwards until the end of the sample and zero otherwise). The first variant tries to capture a temporary effect, while behind the second is the idea of a more permanent effect. To take due account of the crisis within our framework, we distinguish between common (restricting the coefficient to be equal across countries) and country-specific effects. The following results emerge: ${ }^{15}$ First, it is important to model the crisis with a step dummy. Thus, the effects of the crisis seem to be long-lasting and persistent. The impulse dummy does in no case reveal significant results. Second, for all countries together, we get a positive and significant effect of the crisis. However, significant country-specific effects are only found for some countries: a positive effect for Germany, France, Italy and Luxemburg; a negative effect for Spain, Portugal, Finland and the Netherlands. Third, and most important, all other determinants of the net issues included remain significant with the correct sign.

\subsection{The euro area and non-euro area countries}

In this section, we repeat the same analysis for eight non-euro area countries (Australia, Canada, Japan, Norway, Sweden, Switzerland, UK, US) to which we add the total euro area in a second step.For the eight countries, the annual sample can be extended to include the 1990s. In this setup, the cumulated net issues equal currency (banknotes) in circulation (including vault cash). Once again and for every country, we distinguish between small, medium and large denominations. The decision is done on a country-by-country basis. ${ }^{16}$ In any case, we qualify at least one denomination as large, medium and small, respectively (see table 5). As in section 3.1, we control for transaction balances and opportunity costs by including private consumption and a short-term nominal deposit interest rate. The data are from the AMECO database and the respective national central banks. Panel unit root and cointegration tests unambiguously show that all variables are I(1) and that there exists (at least) one cointegration relationship (not shown, but available upon request). ${ }^{17}$

Table 5: Small, medium and large denominations:non-euro area countries

\begin{tabular}{|l|l|l|l|}
\hline & Small & Medium & Large \\
\hline Australia & AUD 10, 5 & AUD 50, 20 & AUD 100 \\
\hline Canada & CAD 10, 5, 2, 1 & CAD 50, 20 & CAD 100 \\
\hline Japan & JPY 2000, 1000, 500 & JPY 5000 & JPY 10000 \\
\hline Norway & NOK 100, 50 & NOK 500, 200 & NOK 1000 \\
\hline Sweden & SEK 50, 20, 10, 5 & SEK 500, 200, 100 & SEK 1000 \\
\hline Switzerland & CHF 20, 10, 5 & CHF 100, 50 & CHF 1000, 500, 200 \\
\hline United Kingdom & GBP 5, 1 & GBP 20, 10 & GBP 50 \\
\hline United States & USD 10, 5, 2,1 & USD 50, 20 & USD 100 \\
\hline
\end{tabular}

Notes: own table.

The pooled cointegration equations are again estimated by DOLS with fixed effects (see table 6). Private consumption as well as the cash variables are in logarithms $(l)$, interest rates and the shadow economy enter the equations in percentage

\footnotetext{
${ }^{15}$ Detailed results available upon request. We also tested several dummies for the euro crisis 2011/12 which, however, did not prove to be significant.

${ }^{16}$ See for a such a procedure Amromin \& Chakravorti (2009) and Fischer et al (2004).

${ }^{17}$ Exceptions of the rule that the null of a unit root in the levels of the variables is rejected are in some cases interest rates and the shadow economy estimate. However, as the null of a unit root is unambiguously rejected for the (logarithmic) change in all the variables, we classify the variables as I(1).
} 
terms. Consequently, we estimate true (semi-) elasticities. Three main conclusions emerge: First, for no cash group are we able to establish a meaningful cash demand equation. This result also holds if we restrict the sample to the period since 2002 as in section 3.1. Second, the results do not differ whether including or excluding the whole euro area. Third, the shadow economy variable is either not significant or has the wrong sign. In this respect, aggregating all euro area countries obviously cushions the different national behaviours. However, it is important to notice once again that the national net issues of countries within a currency union do not correspond to the national cash in circulation. The disappointing result for the non-euro area countries is in line with papers which do not find a reliable and significant relationship between the shadow economy and cash holdings (see, e g, Bartzsch \& Seitz, 2016; Flannigan \& Parsons, 2018; Takala \& Virén, 2010). It also matches the statements in this respect mentioned in the introduction.

Table 6: Pooled Cointegration relationships: non-emu countries with/without euro area

\begin{tabular}{|l|l|l|l|l|l|l|}
\hline Variable & \multirow{2}{*}{$\begin{array}{l}\text { Specifi- } \\
\text { cation }\end{array}$} & & Panel & Explanatory variables & \multicolumn{2}{l|}{} \\
\cline { 4 - 7 } & & se & in & lcons & $\mathrm{R}^{2}$ \\
\hline lcash & $\mathrm{c}$ & without euro area & $-0.06^{* * *}$ & $-0.02^{*}$ & $0.78^{* * *}$ & 0.99 \\
\hline lcash & $\mathrm{c}$ & including euro area & $-0.08^{* * *}$ & $-0.01^{*}$ & $0.74^{* * *}$ & 0.99 \\
\hline lcash_la & $\mathrm{c}$ & without euro area & $-0.15^{* * *}$ & -0.02 & $0.55^{* * *}$ & 0.99 \\
\hline lcash_la & $\mathrm{c}$ & including euro area & $-0.17^{* * *}$ & -0.02 & $0.46^{* * *}$ & 0.99 \\
\hline lcash_mi & $\mathrm{c}$ & without euro area & $-0.02^{*}$ & -0.01 & $0.93^{* * *}$ & 0.99 \\
\hline lcash_mi & $\mathrm{c}$ & including euro area & $-0.02^{* *}$ & -0.01 & $0.90^{* * *}$ & 0.99 \\
\hline lcash_sm & $\mathrm{c}$ & without euro area & -0.01 & $0.01^{* *}$ & $0.33^{* * *}$ & 0.99 \\
\hline lcash_sm & $\mathrm{c}$ & including euro area & -0.01 & $0.01^{*}$ & $0.32^{* * *}$ & 0.99 \\
\hline
\end{tabular}

Notes: Unbalanced panel; sample 1992-2017; pooled DOLS estimates with fixed 1 lead and 1 lag; equations deterministics $\mathrm{c}$ as fixed effects using cross-section weights; $* * *(* *, *): 1(5,10)$ percent significance level.

\subsection{The euro area taken individually and as aggregate}

Concentrating solely on the euro area as a whole enables to consider more potential determinants of cash demand and to switch to quarterly frequency. For comparison purposes, we again present the results of single-equation DOLS estimates (with one lead and lag, respectively) of long-run nominal banknote demand (three different denominational groups). ${ }^{18}$ As potential demand determinants, we include: 1) GDP as well as private consumption as transactions variables; 2) adeposit interest rate as opportunity cost variable; 3 ) the real effective exchange rate of the euro with respect to 38 partner countries to capture foreign demand; 4) the number and value of debit and credit card transactions as alternative payment media and 5) the share of the shadow economy in GDP. The sample runs from 2002.q1 - 2017.q4. All variables except the shadow economy are in logs. ${ }^{19}$

The following results emerge (see Table 7): Only the large denominations seem to be influenced by shadow economic activities and the effect is only marginally significant. An increase in the share of the shadow economy in GDP of one percentage point increases the demand for large denominations by about $1.1 \%$. Foreign demand is present at all denominations. There is a substitution relationship between banknote demand and card payments. It is captured by the number of credit card transactions in the case of medium and large denominations, and by the number of debit card transactions in the case of small denominations. This is not too surprising, given that most of all big items and paid by credit cards. The transactions motive for the large denominations is best modelled by a broad concept, namely GDP whereas private consumption expenditures drive the other denominations. The interest rate is only important for the small and medium denominations. With these specifications, it is not necessary to include a dummy variable for the financial crisis of 2008/09. ${ }^{20}$ Rua (2019) estimates SUR equations for each individual euro denomination and differentiates between the short-run and the long-run. In line with our results, he finds that the transactions motive and the store of value function are relevant across banknote denominations. However, in his approach, the influence of foreign demand is only present

\footnotetext{
${ }^{18}$ FM-OLS estimates yield qualitatively analogous results (available upon request).

${ }^{19}$ With respect to interest rates, this means we estimate true elasticities. The log-log specification yields interest rate semielasticities, which vary with the level of interest rates. The lower interest rates, the higher the interest rate semi-elasticity in absolute terms which introduces a non-linearity in the relationship. Theoretical considerations justify this formulation (Mulligan \& Sala-i-Martin, 2000). Moreover, Chadha et al (1998) show that in the case of well-behaved utility functions, such a functional form follows necessarily from the application of first principles.

${ }^{20}$ Only in the equation for the small denominations would such a dummy variable, modelled as a step dummy, have significant effects without altering the general conclusions.
} 
for the high value denominations. This is at odds with experience. He also analyzes the role of financial and economic policy uncertainty and gets a significant influence for the $€ 50$ banknote, the dominant denomination in the euro area.

Table 7: DOLS estimates of euro area banknote demand

\begin{tabular}{|c|c|c|c|}
\hline Variable & Large & Medium & Small \\
\hline GDP & $5.10^{* * *}$ & & \\
\hline Private consumption & & $4.18^{* * *}$ & $2.33 * * *$ \\
\hline Interest rate & & $-0.19 * * *$ & $-\overline{0.05 * * *}$ \\
\hline Exchange rate & $2.57 * * *$ & $0.51 * * *$ & \\
\hline Cards & $-0.67 * * 1)$ & $\begin{array}{l}-0.53 * * * \\
\text { 1) }\end{array}$ & $\begin{array}{l}-0.67 * * \\
\text { 2) }\end{array}$ \\
\hline SE & $1.08 *$ & & \\
\hline Adj. $R^{2}$ & 0.97 & 0.99 & 0.96 \\
\hline $\begin{array}{l}\text { Phillips Ouliaris } \tau- \\
\text { test }\end{array}$ & $-5.92 * * *$ & $-6.76^{* * *}$ & $-7.73 * * *$ \\
\hline Hansen test & 0.05 & 0.05 & 0.04 \\
\hline
\end{tabular}

Notes: DOLS estimates; sample 2002.q1-2017.q4; all variables except se in logs; *, **, *** indicates significance at the $10 \%, 5 \%$ and $1 \%$ level, respectively. A constant is included in the regression. Phillips-Ouliaris $\tau$-test is a cointegration test with null hypothesis of no cointegration, while Hansen test is a cointegration test with null hypothesis of cointegration. Interest rate: deposits with agreed maturity up to 1 year; exchange rate: real effective exchange rate of the $€$ with respect to 38 partner countries; 1) number of credit card transactions; 2): number of credit and debit card transactions.

The residuals of the three equations seem to be well-behaved and do not show signs of mis-specification, even if there are some outliers at the end of the sample for the medium and large denominations (see Chart 1). 


\section{Chart 1: Residuals of the three equations}

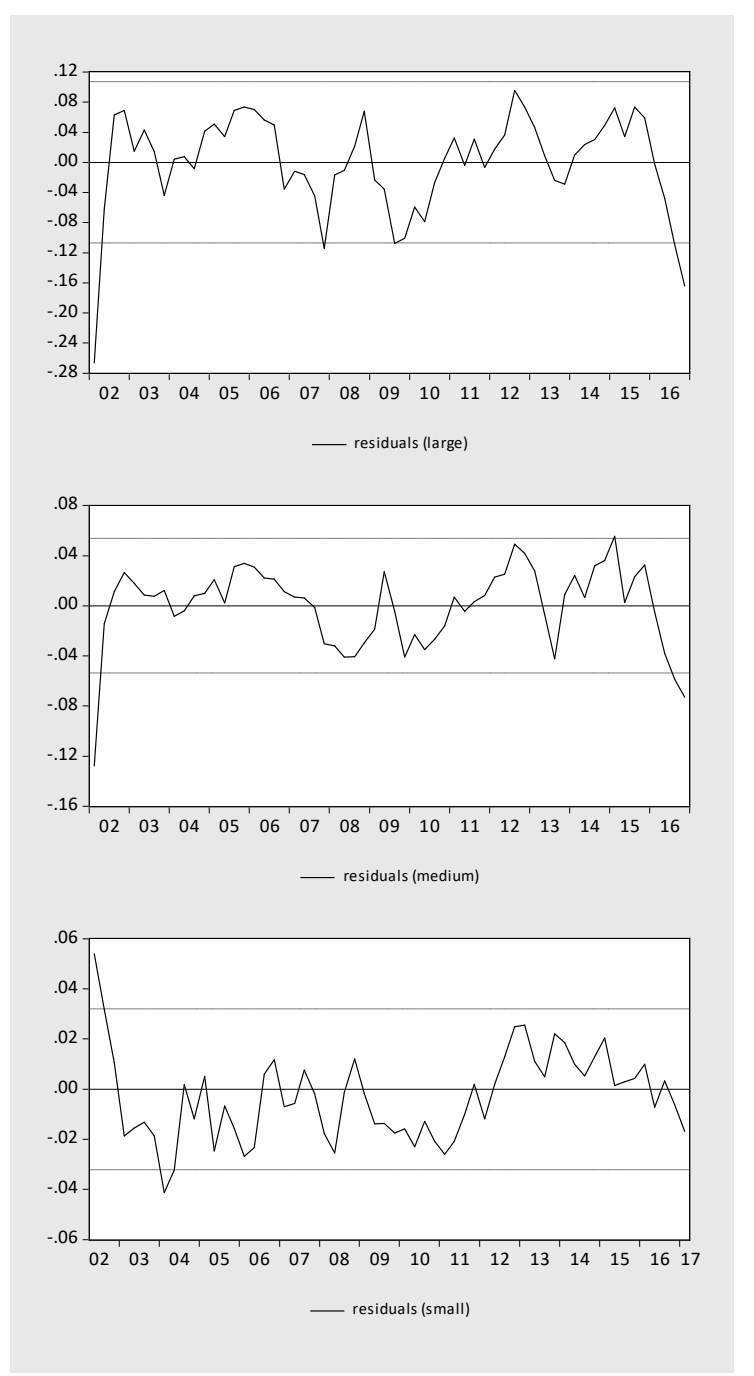

Notes: Residuals with one standard error bands (dotted lines).

\section{Summary and conclusions}

The paper analyzed the importance of the shadow economy for the cash holding in the different euro area countries. Estimates of the shadow economy are only available on an annual basis. Therefore, panel approaches are sensible, e.g. panel unit root and panel cointegrating tests as well as panel estimation methods. To assess the relationship between cash and the shadow economy, it was necessary to control for other motives for holding cash and national peculiarities. To test for robustness different cash breakdowns and two different country groups are considered and a multitude of statistical tests and econometric procedures are performed. Given that some results are sensitive to the concrete specification and the presence of estimation uncertainty it may be concluded that, if at all and in euro area countries, it is the medium denominations which might be influenced positively by shadow economic activities. And it seems that this result is driven by the smaller countries. For the four big euro area countries, we did not get a significant positive coefficient of the shadow economy variable. Furthermore and unfortunately, extending the approach to important western economies and including in the panel the euro area as a whole does not allow to establish a meaningful relationship. Therefore,our starting hypothesis of section 2 of a positive relationship between cash in circulation and the shadow economy had to be rejected in many cases and could only be confirmed for specific denominations and countries. However, due to data limitations and degrees of freedom, we did not model all possible determinants of cash demand explicitly, e.g. the role of cashless substitutes or foreign demand. Therefore, the results should be interpreted with caution.

The paper also demonstrates (like many others) that it is difficult to establish such a relationship against the background of the special characteristics of cash and the shadow economy. With respect to cash, we do not know exactly where it circulates, for what purposes it is held and who holds it. In this sense private consumption or disposable income may not 
be the best proxies for the transaction variable. Moreover, precautionary savings in cash are not addressed. This could be especially important around the financial and economic crisis 2008/09 or during the euro crisis 2012/2013. Furthermore, the shadow economy is a construct which by definition is hard to capture and to estimate. All in all, it seems that cash is probably used to a smaller extent in the context of shadow economic activities than is often suspected and that abolishing or limiting cash would not be as effective as desired in curbing these activities (Mai, 2016; Schneider \& Linsbauer, 2016).

\section{References}

Amromin, G \& S Chakravorti (2009), Whither Loose Change? The Diminishing Demand for Small-Denomination Currency, Journal of Money, Credit and Banking 41, 315-335.

Ardizzi G, Petraglia C\&M Piacenza (2014), Measuring the Underground Economy with the Currency Demand Approach: A Reinterpretation of the Methodology, With an Application to Italy.Review of Income \& Wealth 60, 747-772.

Bartzsch, N, G Rösl\& F Seitz (2013), Currency Movements Within and Outside a Currency Union: The case of Germany and the euro area, The Quarterly Review of Economics and Finance 53, 393- 401.

Bartzsch, N \& F Seitz (2016), Cash Holdings in Germany and the Demand for "German" Banknotes: What Role Is There for Cashless Payments?, in: Górka, J (ed), Transforming Payment Systems in Europe, Palgrave Macmillan, Basingstoke, 111-148.

Bartzsch, N, F Schneider \& M Uhl (2019), Cash Usage in Germany: Macroeconomic estimates on the size of illegal cash usage in Germany, Deutsche Bundesbank Publisher.

Breitung, J (2000) The Local Power of some Unit Root Tests for Panel Data, in: Baltagi,B (ed) Advances in econometrics, Vol. 15: Nonstationary panels, panel cointegration, and dynamic panels, Amsterdam, JAI Press, 161-178.

Buiter, W M (2009), Negative Nominal Interest Rates: Three ways to overcome the zero lower bound, NBER Working Paper 15118, June.

Chadha, J S, A G Haldane \& N GJ Janssen (1998), Shoe-leather Costs Reconsidered, The Economic Journal 108, 363382.

Christiansen, L, A Prati, L A Ricci \& T Tressel (2009), External Balance in Low Income Countries, IMF- Working paper No. 221.

Dalinghaus, U (2017), Keeping Cash: Assessing the arguments about cash and crime, Institute for Money, Technology \& Financial Inclusion.

Dell'Anno, R \& S H Offiong (2008), Shadow Economy and Unemployment Rate in USA: is there a structural relationship? An empirical analysis. Applied Economics 40, 2537-2555.

Deutsche Bundesbank (2016), Cash as a Means of Payment and a Store of Value, Annual Report 2015, 25-45.

Deutsche Bundesbank (2019), Cash Demand in the Shadow Economy, Monthly Report March 2019, 43-58.

Dreher, A, Kotsogiannis, C\&S McCorriston (2007), Corruption around the World: Evidence from a structural model,Journal of Comparative Economics 35, 443-466.

Drehmann, M, C Goodhart \& M Krueger (2002), The Challenges Facing Currency Usage: Will the traditional transactions medium be able to resist competition from the new technologies?, Economic Policy 34, 195-227.

European Central Bank (2018), Trends and Developments in the Use of Euro Cash over the past ten Years, Economic Bulletin,Issue 6/2018, 87-109.

FAZ (2016), Experten zweifeln an Draghis Bargeldbehauptung, 14 April.

Feld. L P \& F Schneider (2010), Survey on the Shadow Economy and Undeclared Earnings in OECD Countries, German Economic Review11, 109-149.

Fischer, B, P Köhler \& F Seitz (2004), The Demand for Euro Area Currencies: Past, present, future, ECB Working Paper No. 330, April.

Flannigan, G \& S Parsons (2018), High-denomination Banknotes in Circulation: A cross-country analysis, Reserve Bank of Australia, Bulletin, March 2018, 14-30. 
Guibourg, G \& B Segendorf (2007), The Use of Cash and the Size of the Shadow Economy in Sweden, Sveriges Riksbank, Working paper Series 204, March.

Gyomai, G.\&P. van de Pen (2014), The Non-observed Economy in the System of National Accounts, OECD Statistics Brief, June 2014, No. 18.

Herwartz, H, J Sardà \& B Theilen (2016), Money Demand and the Shadow Economy: Empirical evidence from OECD countries, Empirical Economics 50, 1627-1645.

Igudia, E, Ackrill, R, Coleman, S \& C Dobson (2016), Determinants of the Informal Economy of an Emerging Economy: A multiple indicator, multiple causes (MIMIC) approach. International Journal of Entrepreneurship and Business $282,154-177$.

Im, K S, M H Pesaran \& Y Shin (2003), Testing for Unit Roots in Heterogenous Panels, Journal of Econometrics 115, 53-74.

Immordino, G \& F F Russo (2018), Cashless Payments and Tax Evasion, European Journal of Political Economy 55, 3643.

Jobst, C \& H Stix (2017), Doomed to Disappear? The surprising return of cash across time and across countries, CEPR Discussion Paper No. 12327, September.

Judson, R A \& R D Porter (2001), Overseas Dollar Holdings: What Do We know?,WirtschaftspolitischeBlätter 4, 431440 .

Juselius, K (2006), The Cointegrated VAR Model: Methodology and applications, Oxford University Press.

Kao, C (1999), Spurious Regression and Residual-based Tests for Cointegration in Panel Data, Journal of Econometrics 90, 1-44.

Kao, C \& M H Chiang (2001), Nonstationary Panels, Cointegration in Panels and Dynamic Panels: A survey, in: Baltagi, B H, T B Fomby\& R C Hill (eds), Nonstationary panels, panel cointegration, and dynamic panels, Vol. 15, 179222.

Klovland, J T (1984), Tax Evasion and the Demand for Currency in Norway and Sweden. Is there a hidden relationship?, The Scandinavian Journal of Economics 86, 423-439.

Krüger, M \& F Seitz (2017), The Benefits of Cash (Module 2), Fritz Knapp Publisher, Frankfurt/Main.

Levin, A, C F Lin \& C Chu (2002), Unit Root Tests in Panel Data: Asymptotic and finite-sample properties, Journal of Econometrics 108, 1-24.

Maddala, G S. \& S Wu (1999). A Comparative Study of Unit Root Tests with Panel Data and a New Simple Test, Oxford Bulletin of Economics and Statistics 61, 631-52.

Mai, H (2016), Cash, Freedom and Crime: Use and impact of cash in a world going digital, Deutsche Bank Research, EU Monitor Global financial markets, 23 November.

Mark, N C \& D Sul (2003), Cointegration Vector Estimation by Panel DOLS and Long-run Money Demand, Oxford Bulletin of Economics and Statistics 65, 655-680.

Medina, L \& F Schneider (2018), Shadow Economies around the World: What did we learn over the last 20 years?, IMF Working Paper 18/17, January.

Mersch, Y (2016), Bares bleibtWahres, guest article for Spiegel Online, 5 May.

Mulligan, C B \& X Sala-i-Martin (2000), Extensive Margins and the Demand for Money at Low Interest Rates, Journal of Political Economy 108, 961-991.

Naga R A \& E Bolzani (2008), Income, Consumption and Permanent Income: A MIMIC Approach to Multidimensional Poverty Measurement, in: Kakwani N\& J Silber (eds) Quantitative Approaches to Multidimensional Poverty Measurement. Palgrave Macmillan, London, 104-117.

Orsi, R, Raggi, D \&F Turino (2014), Size, Trend, and Policy Implications of the Underground Economy, Review of Economic Dynamics 17, 417-436. 
Pedroni, P (2001), Purchasing Power Parity Tests in Cointegrated Panels, Review of Economics and Statistics 83, 727 731.

Pedroni, P (2004), Panel Cointegration: Asymptotic and finite sample properties of pooled time series tests with an application to the PPP hypothesis, Econometric Theory 20, 597-625.

Pickhardt M \& J Sardà (2012), Cash, Hoarding and the Underground Economy, in: Deutsche Bundesbank (ed), The usage, costs and benefits of cash: Theory and evidence from macro and micro data, International Cash Conference 2012, BonifatiusDruck und Buch Verlag, 15-45.

Pickhardt, M \&J Sardà (2013), Size and Causes of the Underground Economy in Spain: A correction of the record and new evidence from the MCDR approach, European Journal of Law \& Economics39, 1-27.

Phillips, P C B \& B E Hansen (1990), Statistical Inference in Instrumental Variables Regression with I(1) Processes, Review of Economic Studies 57, 99-125.

Rogoff, K S (1998), Blessing or Curse? Foreign and underground demand for euro notes, Economic Policy, 263-303.

Rogoff, K S (2016), The Curse of Cash, Princeton University Press, Princeton and Oxford.

Rua, A (2018), Modelling Currency Demand in a Small Open Economy within a Monetary Union, Economic Modelling $74,88-96$.

Rua, A (2019), Modelling the Demand for Euro Banknotes, Banco de Portugal, Working Paper 2019-5, February.

Sands, P (2016), Making it Harder for the Bad Guys: The case for eliminating high denomination notes, M-RCBG Associate Working Paper Series No 52, February.

Sands, P, B Weisman, H Campbell \& T Keatinge (2017), Limiting the Use of Cash for Big Purchases: Assessing the case for uniform cash thresholds, in: Deutsche Bundesbank (ed), War on cash: Is there a future for cash?, Lehn Publisher, 686-741.

Schneeweiss, Z (2016), Bloomberg: ECB wants proof that 500-euro note helps criminals, Mersch says, 4 February.

Schneider, F (2016), Payment Habits and the Use of Cash in Austria: An empirical investigation, Working paper, July.

Schneider, F (2017), Restricting or Abolishing Cash: An effective instrument for fighting the shadow economy, crime and terrorism?, in: Deutsche Bundesbank (ed), War on cash: Is there a future for cash?, Lehn Publisher, 44-91.

Schneider, F, \& D H Enste (2000), Shadow Economies: Size, causes, and consequences, Journal of Economic Literature 38, 77-114.

Stock, J H \& M Watson (1993), A Simple Estimator of Cointegrating Vectors in Higher Order Integrated Systems, Econometrica 61, 783-820.

Takala, K \& M Virén (2010), Is Cash Used only in the Shadow Economy?, International Economic Journal 24, 525-540.

Schneider, F \& K Linsbauer (2016), The Financial Flows of Transnational Crime and Tax Fraud: How much cash is used and what do we (not) know?, in: Beer, C, E Gnan \& U W Birchler (eds), Cash on trial, SUERF Conference Proceedings 2016/1, Larcier, 83-107.

United Nations et al (2009), System of National Accounts 2008, New York.

Wagner, M \& J Hlouskova (2012), The Performance of Panel Cointegration Methods: Results from a large scale simulation study, Econometric Reviews 29, 182-223.

Williams, C C (2005), The Undeclared Sector, Self-Employment and Public Policy. International Journal of Entrepreneurial Behaviour\& Research 11, 244-257.

Williams, C C \& F Schneider (2016), Measuring the Global Shadow Economy: The prevalence of informal work and labour, Edward Elgar Publishing.

Table 1A: Shadow economy in relation to GDP (SE) in \% 
Appendix A: Some descriptive statistics

Table 1A: Shadow economy in relation to GDP (SE) in \%

$\begin{array}{lllll}\text { Variable } & \text { Mean } & \text { Minimum } & \text { Maximum } & \text { Std. Dev. } \\ \text { SE_AT } & 9.5 & 7.0 & 12.5 & 1.96 \\ \text { SE_BE } & 22.8 & 21.6 & 24.0 & 0.74 \\ \text { SE_DE } & 14.4 & 11.4 & 16.3 & 1.33 \\ \text { SE_EE } & 25.3 & 21.6 & 30.4 & 2.96 \\ \text { SE_ES } & 24.3 & 22.4 & 26.3 & 1.49 \\ \text { SE_FI } & 17.8 & 16.54 & 18.9 & 0.75 \\ \text { SE_FR } & 15.5 & 14.0 & 16.6 & 0.70 \\ \text { SE_GR } & 29.8 & 26.8 & 33.0 & 1.97 \\ \text { SE_IE } & 15.4 & 13.5 & 16.8 & 0.89 \\ \text { SE_IT } & 29.1 & 26.8 & 31.7 & 1.31 \\ \text { SE_LU } & 10.3 & 9.4 & 11.0 & 0.48 \\ \text { SE_LV } & 22.6 & 18.3 & 28.9 & 3.00 \\ \text { SE_NL } & 13.5 & 11.7 & 14.5 & 0.70 \\ \text { SE_PT } & 23.2 & 21.0 & 25.0 & 0.99 \\ \text { SE_SL } & 23.5 & 19.5 & 26.4 & 2.04 \\ \text { SE_SK } & 14.3 & 12.5 & 18.4 & 1.93\end{array}$

Table 2A: Total cash issues ( $€$ bn)

$\begin{array}{lllll} & \text { Mean } & \text { Minimum } & \text { Maximum } & \text { Std. Dev. } \\ \text { CASH_AT } & -0.3 & -20.4 & 15.2 & 10.2 \\ \text { CASH_BE } & 9.1 & -2.4 & 27.9 & 10.1 \\ \text { CASH_DE } & 345.0 & 100.0 & 610.0 & 153.0 \\ \text { CASH_EE } & 0.9 & 0.35 & 1.3 & 0.3 \\ \text { CASH_ES } & 62.2 & 25.3 & 84.3 & 17.9 \\ \text { CASH_FI } & 8.8 & 2.3 & 14.9 & 4.0 \\ \text { CASH_FR } & 75.1 & 30.7 & 123.0 & 29.2 \\ \text { CASH_GR } & 25.6 & 7.6 & 46.1 & 13.6 \\ \text { CASH_IE } & 21.7 & 4.2 & 34.1 & 9.9 \\ \text { CASH_IT } & 119.0 & 54.4 & 145.0 & 29.7 \\ \text { CASH_LU } & 58.3 & 5.5 & 97.2 & 29.9 \\ \text { CASH_LV } & 0.4 & 0.1 & 0.6 & 0.2 \\ \text { CASH_NL } & 17.6 & 9.9 & 22.6 & 4.7 \\ \text { CASH_PT } & -1.4 & -13.5 & 4.9 & 6.3 \\ \text { CASH_SL } & 1.9 & 0.4 & 4.9 & 1.5 \\ \text { CASH_SK } & 8.0 & 3.5 & 11.4 & 2.5\end{array}$


Table 3A: Large denominations (€ bn)

$\begin{array}{lllll}\text { Variable } & \text { Mean } & \text { Minimum } & \text { Maximum } & \text { Std. Dev. } \\ \text { CASHLA_AT } & 36.0 & 7.7 & 76.2 & 23.6 \\ \text { CASHLA_BE } & -9.0 & -13.2 & 1.6 & 3.9 \\ \text { CASHLA_DE } & 129.0 & 35.2 & 199.0 & 52.3 \\ \text { CASHLA_EE } & 0.7 & 0.2 & 0.9 & 0.3 \\ \text { CASHLA_ES } & 43.2 & 13.7 & 60.5 & 15.0 \\ \text { CASHLA_FI } & 2.4 & 0.5 & 3.4 & 1.0 \\ \text { CASHLA_FR } & 1.6 & -11.8 & 6.8 & 5.9 \\ \text { CASHLA_GR } & 1.6 & -1.8 & 4.1 & 1.5 \\ \text { CASHLA_IE } & 0.1 & -0.4 & 0.4 & 0.2 \\ \text { CASHLA_IT } & 2.1 & -46.8 & 22.1 & 22.6 \\ \text { CASHLA_LU } & 48.3 & 4.8 & 76.3 & 23.2 \\ \text { CASHLA_LV } & -0.3 & -0.7 & -0.0 & 0.3 \\ \text { CASHLA_NL } & 7.5 & 0.6 & 11.7 & 3.8 \\ \text { CASHLA_PT } & -0.5 & -1.4 & 0.1 & 0.6 \\ \text { CASHLA_SL } & 0.4 & 0.1 & 0.8 & 0.3 \\ \text { CASHLA_SK } & 3.1 & 1.2 & 4.3 & 1.0\end{array}$

Table 4A: Medium denominations ( $€$ bn)

$\begin{array}{lllll}\text { Variable } & \text { Mean } & \text { Minimum } & \text { Maximum } & \text { Std. Dev. } \\ \text { CASHMI_AT } & -32.5 & -67.2 & 5.8 & 26.8 \\ \text { CASHMI_BE } & 18.4 & 4.2 & 42.8 & 12.5 \\ \text { CASHMI_DE } & 167.0 & 48.8 & 320.0 & 78.0 \\ \text { CASHMI_EE } & 0.2 & 0.1 & 0.5 & 0.2 \\ \text { CASHMI_ES } & 37.0 & 26.0 & 48.0 & 6.7 \\ \text { CASHMI_FI } & 4.4 & 0.8 & 8.8 & 2.5 \\ \text { CASHMI_FR } & 31.9 & 11.9 & 66.2 & 17.1 \\ \text { CASHMI_GR } & 26.0 & 4.8 & 51.5 & 16.0 \\ \text { CASHMI_IE } & 20.5 & 2.7 & 34.6 & 10.6 \\ \text { CASHMI_IT } & 112.0 & 37.6 & 187.0 & 45.1 \\ \text { CASHMI_LU } & 11.1 & 0.7 & 22.9 & 7.6 \\ \text { CASHMI_LV } & 0.4 & 0.3 & 0.4 & 0.0 \\ \text { CASHMI_NL } & 15.8 & 6.6 & 22.4 & 4.5 \\ \text { CASHMI_PT } & -8.1 & -23.6 & 1.9 & 8.6 \\ \text { CASHMI_SL } & -1.5 & -2.3 & -0.1 & 0.7 \\ \text { CASHMI_SK } & 4.1 & 2.0 & 6.1 & 1.2\end{array}$


Table 5A: Small denominations (€ bn)

$\begin{array}{lllll}\text { Variable } & \text { Mean } & \text { Minimum } & \text { Maximum } & \text { Std. Dev. } \\ \text { CASHSM_AT } & -3.8 & -9.6 & 1.6 & 4.0 \\ \text { CASHSM_BE } & -0.3 & -1.5 & 1.6 & 0.9 \\ \text { CASHSM_DE } & 49.3 & 16.0 & 91.9 & 23.4 \\ \text { CASHSM_EE } & -0.1 & -0.1 & 0.1 & 0.1 \\ \text { CASHSM_ES } & -18.0 & -46.2 & 8.4 & 17.1 \\ \text { CASHSM_FI } & 2.1 & 0.9 & 3.0 & 0.6 \\ \text { CASHSM_FR } & 41.6 & 13.2 & 68.9 & 17.8 \\ \text { CASHSM_GR } & -2.0 & -7.4 & 2.7 & 3.1 \\ \text { CASHSM_IE } & 1.1 & -0.2 & 2.0 & 0.7 \\ \text { CASHSM_IT } & 4.7 & 3.3 & 9.2 & 1.7 \\ \text { CASHSM_LU } & -1.0 & -2.0 & 0.0 & 0.7 \\ \text { CASHSM_LV } & 0.4 & 0.3 & 0.4 & 0.0 \\ \text { CASHSM_NL } & -5.7 & -13.0 & 1.5 & 4.6 \\ \text { CASHSM_PT } & 7.2 & 2.7 & 11.5 & 3.0 \\ \text { CASHSM_SL } & 2.9 & 0.5 & 5.0 & 1.5 \\ \text { CASHSM_SK } & 0.8 & 0.4 & 1.0 & 0.2\end{array}$


Table 6A: Correlation of annual cash changes

\begin{tabular}{|c|c|c|c|c|c|c|c|c|c|c|c|c|c|c|c|c|}
\hline & $\mathrm{AT}$ & $\mathrm{BE}$ & $\mathrm{DE}$ & $\mathrm{EE}$ & ES & FI & FR & GR & IE & IT & LU & LV & $\mathrm{NL}$ & $\mathrm{PT}$ & SL & SK \\
\hline AT & 1.00 & 0.05 & -0.18 & 0.83 & -0.07 & -0.15 & -0.04 & 0.38 & -0.19 & -0.16 & -0.28 & -0.09 & -0.13 & 0.97 & -0.06 & 0.16 \\
\hline $\mathrm{BE}$ & 0.05 & 1.00 & -0.31 & 0.89 & -0.40 & -0.40 & -0.32 & 0.03 & -0.41 & -0.372 & 0.98 & -0.14 & -0.28 & 0.18 & -0.67 & 0.98 \\
\hline $\mathrm{DE}$ & -0.18 & -0.31 & 1.00 & -0.24 & 0.71 & 0.86 & 0.90 & 0.14 & 0.87 & 0.83 & 0.78 & 0.97 & 0.95 & -0.22 & 0.50 & -0.68 \\
\hline $\mathrm{EE}$ & 0.83 & 0.89 & -0.24 & 1.00 & 0.73 & -0.18 & 0.78 & 0.22 & -0.83 & 0.27 & -0.73 & 0.13 & -0.09 & 0.99 & -0.95 & 0.91 \\
\hline ES & -0.07 & -0.40 & 0.71 & 0.73 & 1.00 & 0.91 & 0.82 & 0.40 & 0.90 & 0.87 & 0.98 & 0.66 & 0.80 & -0.10 & -0.02 & 0.71 \\
\hline FI & -0.15 & -0.40 & 0.86 & -0.18 & 0.91 & 1.00 & 0.90 & 0.29 & 0.98 & 0.97 & -0.96 & 0.80 & 0.93 & -0.21 & 0.25 & 0.90 \\
\hline FR & -0.04 & -0.32 & 0.90 & 0.78 & 0.82 & 0.90 & 1.00 & 0.17 & 0.87 & 0.89 & -1.00 & 0.91 & 0.94 & -0.11 & 0.15 & 0.72 \\
\hline GR & 0.38 & 0.03 & 0.14 & 0.22 & 0.40 & 0.29 & 0.17 & 1.00 & 0.21 & 0.22 & 0.96 & 0.15 & 0.19 & 0.39 & -0.26 & 0.50 \\
\hline IE & -0.19 & -0.41 & 0.87 & -0.83 & 0.90 & 0.98 & 0.87 & 0.21 & 1.00 & 0.96 & 0.47 & 0.79 & 0.93 & -0.23 & 0.33 & 0.93 \\
\hline IT & -0.16 & -0.37 & 0.83 & 0.27 & 0.87 & 0.97 & 0.89 & 0.22 & 0.96 & 1.00 & -0.85 & 0.77 & 0.92 & -0.20 & 0.07 & 0.44 \\
\hline LU & -0.28 & 0.98 & 0.78 & -0.73 & 0.98 & -0.96 & -1.00 & 0.96 & 0.47 & -0.85 & 1.00 & 0.92 & -0.23 & 0.73 & 0.91 & -0.81 \\
\hline LV & -0.09 & -0.14 & 0.97 & 0.13 & 0.66 & 0.80 & 0.91 & 0.15 & 0.79 & 0.77 & 0.92 & 1.00 & 0.94 & -0.13 & 0.33 & 0.59 \\
\hline NL & -0.13 & -0.28 & 0.95 & -0.09 & 0.80 & 0.93 & 0.94 & 0.19 & 0.93 & 0.92 & -0.23 & 0.94 & 1.00 & -0.18 & 0.29 & 0.61 \\
\hline PT & 0.97 & 0.18 & -0.22 & 0.99 & -0.10 & -0.21 & -0.11 & 0.39 & -0.23 & -0.20 & 0.73 & -0.13 & -0.18 & 1.00 & -0.28 & 0.13 \\
\hline SL & -0.06 & -0.69 & 0.50 & -0.95 & -0.02 & 0.25 & 0.15 & -0.26 & 0.33 & 0.07 & 0.91 & 0.33 & 0.29 & -0.28 & 1.00 & -0.29 \\
\hline SK & 0.16 & 0.98 & -0.68 & 0.91 & 0.70 & 0.90 & 0.72 & 0.50 & 0.93 & 0.44 & -0.81 & 0.59 & 0.61 & 0.13 & -0.29 & 1.00 \\
\hline
\end{tabular}




\section{Appendix B: The definition of the shadow economy and the MIMIC estimation procedure}

\section{B1: the definition of the shadow economy}

To define shadow economy activities, we follow Gyomai \& van de Pen (2014) and start with a classification for measuring the non-observed economy as follows (Gyomai \&van de Ven, 2014, 1):

(i) Underground hidden production: Activities that are productive and legal, but deliberately concealed from public authorities.

(ii) Illegal production: Productive activities forbidden by law or unlawful when carried out by unauthorized procedures.

(iii) Informal sector production: Productive activities conducted by unincorporated enterprises in the household sector or other units that are unregistered and/or less than a specified size in terms of employment, and have some market production.

(iv) Production of households for own final use: Productive activities that result in goods or services consumed or capitalized by the households that produced them

(v) Statistical "underground": All productive activities that should be accounted for in basic data collection programs, but are missed due to deficiencies in the statistical system.

In order to get exhaustive estimates,we refer to the System of National Accounts (SNA) which differentiates between two basic activities:

(1) Hidden economy (UN et al., 2009, § 6.40): activities that clearly fall in the production boundary of the SNA and are deliberately concealed from public authorities,

(i) to avoid the payment of income, value added or other payments;

(ii) to avoid the payment of social security contributions;

(iii) to avoid having to meet certain legal standards such as minimum wages, maximum hours, safety or health standards, etc.;

(iv) to avoid complying with certain administrative procedures, such as completing statistical questionnaires or other administrative forms.

(2) Illegal activities (UN et al., 2009, § 6.43) which comprise

(i) the production of goods or services whose sale, distribution or possession is forbidden by law;

(ii) production activities that are usually legal but become illegal when carried out by unauthorized producers; for example, unlicensed medical practitioners.

\section{B2: A short explanation of the MIMIC estimation procedure}

The MIMIC (Multiple Indicators and Multiple Causes) model is a special form of a structural equation model and is used to analyze unobservable variables, such as corruption, black market activities and certain other unobservables. ${ }^{21}$ The idea of the MIMIC model is to examine the relationships between a latent variable, e.g. "size of shadoweconomy", and observable variables by using their covariance information (Schneider \& Buehn, 2018). The equation capturing the causes of the latent variable is called the structural model, the equation modelling the consequences of shadow economy is called the measurement model, see equations (1A) and (2A).

Measurement model: $\boldsymbol{y}=\gamma \eta+\boldsymbol{u} \quad$ (1A)

Structural model: $\boldsymbol{\eta}=\beta^{\prime} \boldsymbol{x}+\boldsymbol{\varepsilon}(2 \mathrm{~A})$

${ }^{21}$ In the case of corruption see Dreher et al (2007) and Dreher \& Schneider (2010). Multi dimensional poverty is analyzed with this approach by Naga \& Bolzani (2008). The MIMIC model to estimate the shadow economy is used by Dell'Anno \& Solomon (2008), Feld \& Schneider (2010), Schneider \& Enste (2013). 
In these equations, $\eta$ is the latent variable, which, in our case, represents the shadow economy; $y^{\prime}\left(y_{1}, y_{2}, \ldots, y_{n}\right)^{\prime}$ is a set of observable indicator variables of the shadow economy, which represents the consequences of shadow economy. And $\gamma=\left(\gamma_{1}, \gamma_{2}, \ldots, \gamma_{n}\right)^{\prime}$ is the variation in the indicator variable after a unit change in the latent variable, $\boldsymbol{u}^{\prime}\left(\boldsymbol{u}_{1}, \boldsymbol{u}_{2}, \ldots, \boldsymbol{u}_{n}\right)^{\prime}$ is an error term with zero mean, $\boldsymbol{x}=\left(\boldsymbol{x}_{1}, \boldsymbol{x}_{2}, \ldots, \boldsymbol{x}_{n}\right)^{\prime}$ is a set of observable causal variables of the shadow economy, $\boldsymbol{\beta}^{\prime}=\left(\boldsymbol{\beta}_{1}, \boldsymbol{\beta}_{2}, \ldots, \boldsymbol{\beta}_{n}\right)^{\prime}$ refers to the variation in the latent variable after a unit change in the causal variable, $\varepsilon$ is the stochastic disturbance term.Botherror terms are independent of each other.

The measurement model shows how the observable endogenous variables are affected by the latent variables. The structural model expresses the relationship between the latent variable and its exogenous causal variables. Because the latent variable $\eta$ is unobserved, the structural parameters $\beta$ cannot be estimated directly. After substituting formula (2A) into formula (1A), the MIMIC model can be regarded as a simplified multivariate regression model (3A):

$\boldsymbol{y}=\prod^{\prime} \boldsymbol{x}+\boldsymbol{z}$

In (3A), Ths the coefficient matrix $\not \beta^{\prime}$ in compact form and $z$ is the disturbance vector, with $z=\gamma \varepsilon+u$. The covariance matrix $\theta$ of the disturbance term $\varepsilon, \theta_{\varepsilon}$, reads as:

$\theta_{\varepsilon}=E\left[(\gamma \varepsilon+u)(\gamma \varepsilon+u)^{\prime}\right]=\gamma \gamma^{\prime} \sigma_{\varepsilon}^{2}+\theta_{u}$

In (4A), $\theta_{u}$ is the covariance matrix of the error term $u ; \sigma_{\varepsilon}^{2}$ is the variance of the disturbance term $\varepsilon$. Evidently, the rank of the simplified matrix $\Pi$ in formula $(3 \mathrm{~A})$ is equal to that in formula (1A). The covariance matrix of the disturbance term $\theta_{\varepsilon}$, as the sum of the single rank matrix and the diagonal matrix, is also equal to the rank of formula (1A). Before estimating the simplified model, we need to preset one element of the vector $\gamma$ equal to $1 .{ }^{22}$

The original hypothesis about the statistical quantity $\chi^{2}$ in the structural equation model is

$H_{0}: S=\hat{\Sigma}$. When Maximum likelihood is used to estimate the model, the formula for $\chi^{2}$ and $F$ is as in (5A):

$\chi^{2}=(n-1) F(S ; \hat{\Sigma})$

$F(S ; \hat{\Sigma})=\operatorname{tr}\left(S \hat{\Sigma}^{-1}\right)+\lg |\hat{\Sigma}|-\lg |S|-\rho$

In (5A), $\rho=p+q$ represents the number of observable variables, and $\Sigma$ is the covariance matrix of the hypothetical model in the sample. If $\hat{\Sigma}$ equals the $S$ matrix of the observed data, $\operatorname{tr}=\operatorname{tr}(I)=\rho$. Therefore, $F(S, \hat{\Sigma})=0$. If the model is correctly specified and feasible, we can use Maximum Likelihood to estimate the coefficient matrix including the parameter vectors $\gamma$ and $\beta$. If the mean of the error term $\varepsilon$ is 0 , the order value of the potential variable $\eta$ can be calculated with (2A). This, in turn, generates the shadow economy index.

Three steps are required to estimate the size of the shadow economy with the MIMIC approach. First, analyze the causal and indicator variables of the shadow economy and set-up the MIMIC model to measure its size. Second, run the MIMIC regression and select the best model by comparing their fit. Third, calculate the index of the shadow economy according to the best (selected) estimation model and calibrate the results with respect to the size of the shadow economy for a known year.

\footnotetext{
${ }^{22}$ In estimating the model, one indicator variable should be set as a benchmark indicator for interpretational purposes in nonstandardized estimates. The selected indicator variable should be in a positively correlated to the potential variable. For instance, if $\gamma_{i}=1$, then $y_{i}=\eta+\varepsilon_{i}$. If the estimation coefficient is standardized, there will be no benchmark problem.
} 


\section{Appendix C: Alternative estimation strategies}

\section{C1: Including a deterministic trend}

The following table 1C summarizes the effects of including country-specific linear trends in the cointegration relation. To simplify, only the results (significant (+)/not significant (-)) of the shadow economy variable are shown.

Table 1C: Cointegrating relationships,individual linear trends and the shadow economy

\begin{tabular}{|l|l|l|}
\hline All countries & Specification & se \\
\hline cash & c, no weights & - \\
\hline cash & c, weights & $* *$ \\
\hline cash_la & c, ind. Trend, no weights & - \\
\hline cash_la & c, ind. Trend, weights & $* * *$ \\
\hline cash_mi & c, ind. Trend, no weights & - \\
\hline cash_mi & c, ind. Trend, weights & - \\
\hline cash_sm & c, ind. Trend, no weights & - \\
\hline cash_sm & c, ind. Trend, weights & - \\
\hline Big four & & \\
\hline cash & c, weights & $* * *$ \\
\hline cash_la & c, weights & $* * *$ \\
\hline cash_mi & c, weights & - \\
\hline cash_sm & c, weights & - \\
\hline Small countries & & \\
\hline cash & c, weights & $* *$ \\
\hline cash_la & c, weights & $*$ \\
\hline cash_mi & c, weights & - \\
\hline cash_sm & c, weights & $* * *$ \\
\hline
\end{tabular}

Notes: Pooled DOLS estimates with fixed 1 lead and 1 lag.Only significant positive effects; ${ }^{* * *}(* *, *): 1(5,10)$ percent significance level. -: no significant positive effect. 


\section{C2: Estimates in first differences}

Table $2 \mathrm{C}$ shows the results of the shadow economy variable in pooled least squares estimates in first differences.

Table 2C:Estimates in first differences: all euro area countries

\begin{tabular}{|c|c|c|}
\hline & Specification & se \\
\hline $\mathrm{D}$ (cash) & c, noweights & $*$ \\
\hline $\mathrm{D}$ (cash_la) & c, noweights & $* *$ \\
\hline D(cash_la) & $\mathrm{c}$, weights & - \\
\hline $\mathrm{D}($ cash_mi) & c,noweights & - \\
\hline $\mathrm{D}$ (cash_mi) & $\mathrm{c}$, weights & - \\
\hline D(cash_sm) & $\mathrm{c}$, weights & $* * *$ \\
\hline \multicolumn{3}{|l|}{ Big four } \\
\hline $\mathrm{D}$ (cash) & c, noweights & *** \\
\hline $\mathrm{D}$ (cash) & c, weights & $* * *$ \\
\hline D(cash la) & c, noweights & $* * *$ \\
\hline $\mathrm{D}($ cash_sm) & $\mathrm{c}$, weights & - \\
\hline \multicolumn{3}{|c|}{ Small countries } \\
\hline $\mathrm{D}$ (cash) & $\mathrm{c}$, noweights & $*$ \\
\hline $\mathrm{D}$ (cash) & c, weights & - \\
\hline D(cash_la) & $\mathrm{c}$, noweights & - \\
\hline D(cash_la) & c, weights & - \\
\hline $\mathrm{D}($ cash_mi) & c, noweights & - \\
\hline $\mathrm{D}$ (cash mi) & $\mathrm{c}$, weights & - \\
\hline $\mathrm{D}$ (cash_sm) & $\mathrm{c}$, noweights & $*$ \\
\hline $\mathrm{D}($ cash_sm) & c,weights & - \\
\hline
\end{tabular}

Notes: Unbalanced panel; pooled least squares. Only significant positive effects; *** $(* *, *): 1(5,10)$ percent significance level. -: no significant positive effect. 